\title{
Nutrition in Clinical Practice
}

\section{Prognostic value of the ESPEN consensus and guidelines for malnutrition: \\ Prediction of post-discharge clinical outcomes in older inpatients}

\begin{tabular}{|c|c|}
\hline Journal: & Nutrition in Clinical Practice \\
\hline Manuscript ID & NCP-2017-07-189.R2 \\
\hline Manuscript Type: & Clinical Research \\
\hline Keywords: & $\begin{array}{l}\text { Geriatrics }<\text { Life Cycle, Nutrition assessment }<\text { Nutrition, Rehabilitation }< \\
\text { Research and Diseases, Weight loss }<\text { Research and Diseases, Postacute, } \\
\text { Readmissions, Mortality }\end{array}$ \\
\hline Abstract: & 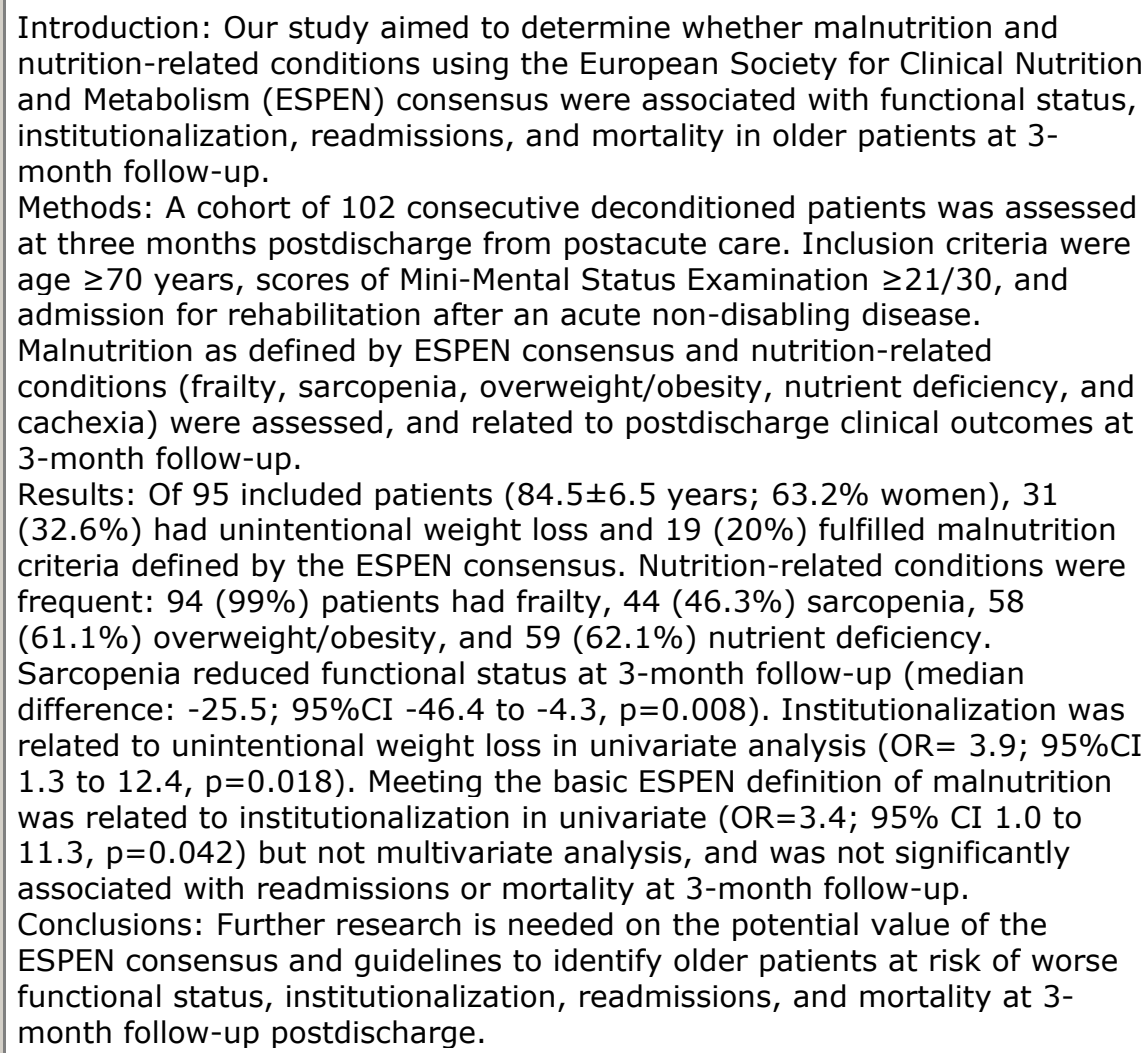 \\
\hline
\end{tabular}


2

(1)

(2)

(3)

(2)

9

6

38

(




\section{INTRODUCTION}

5 Malnutrition is associated with poor functional status and increased mortality in older 6 people (1)(2)(3). The main consequences of malnutrition and its related syndromes, 7 such as frailty or sarcopenia, include increased risks of infections (4)(5), loss of 8 independence (6), worsening health-related quality of life (7), and death (8)(9)(10)(11).

9 Given the lack of consensual malnutrition guidelines, the European Society for Clinical 10 Nutrition and Metabolism (ESPEN) recently made an effort to establish a definition of 11 malnutrition that would be applicable in all adult age-ranges and healthcare settings, 12 independent of etiology (1). The ESPEN consensus definition of malnutrition guidelines 13 on definition and diagnoses has provided clinicians and researchers a practical tool for 14 the hierarchical organization of nutrition disorders, nutrition-related conditions, and 15 nutrition-related syndromes (2).

16 The ESPEN consensus definition of malnutrition has been applied in both acute $17(11)(12)(13)$ and postacute care (14)(15). In a large population of hospitalized older 18 patients with diabetes, malnutrition lengthened the hospital stay, increased the 19 probability of in-hospital death by a factor of 2.7 , and decreased the probability of being 20 discharged home rather than to an institution (13). Early management of nutrition 21 disorders and nutrition-related conditions (1), once detected, could improve the life 22 course of patients (16)(17). 
1

2

3

4

5

6

7

8

9

10

11

12

13

14

15

16

17

18

19

20

21

22

23

24

25

26

27

28

29

30

31

32

33

34

35

36

37

38

39

40

41

42

43

44

45

46

47

48

49

50

51

52

53

54

55

56

57

58

59

60

23 The objective of this longitudinal study was to determine whether the malnutrition and

24 nutrition-related conditions diagnosed during hospitalization using the ESPEN

25 consensus definition were associated with post-discharge clinical outcomes (functional

26 status assessed by Barthel index, institutionalization, hospital readmissions, and

27 mortality) among older patients at 3-month follow-up. 


\section{METHODS}

\section{Design}

30 Cohort study of postacute inpatients who participated in a larger prospective study on

31 malnutrition and sarcopenia (14). The Strengthening the Reporting of Observational

32 Studies in Epidemiology (STROBE) Statement (18) was followed (Additional file 1).

\section{Setting}

34 The study was conducted in a postacute geriatric rehabilitation care unit in a university 35 hospital. The unit focuses specifically on a 2-week period of rehabilitation and 36 functional recovery, after which patients are expected to be discharged home.

\section{Participants}

38 Consecutive patients aged $\geq 70$ years hospitalized in the postacute geriatric rehabilitation 39 care unit due to functional loss resulting from a non-disabling medical disease were 40 included from January to August 2011. Patients with general and/or cognitive conditions 41 (Mini-Mental State Examination score <21/30) that prevented completion of the 42 diagnostic tests or absence of information regarding weight loss in the previous year 43 were excluded.

\section{$44 \quad$ Procedure}

45 All inpatients were screened for risk of malnutrition at admission by the Mini46 Nutritional Assessment Short-Form (MNA-SF) (19)(20). The diagnosis of malnutrition 47 as defined by the ESPEN consensus was then retrospectively applied in all patients 48 identified as at risk of malnutrition (MNA-SF scores $\leq 11$ ). The ESPEN definition pro- 
49 poses two alternative ways to diagnose malnutrition: body mass index (BMI) $<18.5$

$50 \mathrm{~kg} / \mathrm{m}^{2}$ (alternative 1) or unintentional weight loss ( $>10 \%$ indefinite of time, or $>5 \%$ over

51 the last 3 months) combined with age-related BMI (BMI $<20 \mathrm{~kg} / \mathrm{m}^{2}$ in $<70$ years, or $52<22 \mathrm{~kg} / \mathrm{m}^{2}$ in $\geq 70$ years $)$ or fat-free mass index $\left(<17 \mathrm{~kg} / \mathrm{m}^{2}\right.$ in men and $15 \mathrm{~kg} / \mathrm{m}^{2}$ in women) (1). Unintentional weight loss was obtained from medical records. If data for the last 3 months were unavailable, weight loss was assessed by patient and caregiver 55 interview or from weight data recorded in the medical record during the last year. BMI 56 was calculated from height and weight $\left(\mathrm{kg} / \mathrm{m}^{2}\right)$ : height was measured in all patients able 57 to stand safely, otherwise a knee height equation (21) was applied; body weight was 58 measured to the nearest $0.1 \mathrm{~kg}$. Fat-free mass (FFM), expressed in $\mathrm{kg}$, was measured 59 by bioimpedance (Bodystat 1500, Bodystat Ltd., Isle of Man British Isles) as previously 60 described (14)(22). The FFM values were divided by height squared to obtain the fat61 free mass index (FFMI), expressed in $\mathrm{kg} / \mathrm{m}^{2}$ and compared with those of the reference 62 population (23).

63 Nutrition-related conditions (sarcopenia, frailty, overweight/obesity, and nutrient deficiency) were also considered (1). The term "nutrition-related syndrome" was used to refer to a condition included in the definition, such as sarcopenia and frailty that is also

66 identified as a geriatric syndrome. Sarcopenia was assessed following The European

67 Working Group on Sarcopenia in Older People (EWGSOP) criteria: low muscle mass in presence of low muscle function or low physical performance (24) assessed with bioimpedance analysis, isometric handgrip dynamometry, and gait speed in a 4-m walk test as previously described (14)(22). Gait speed was considered $0 \mathrm{~m} / \mathrm{s}$ in bedridden

71 patients unable to stand. Frailty was assessed by the Frailty Phenotype (25) in presence 
72 of three of the following criteria: weight loss, weakness, exhaustion, slow walking

73 speed, and low physical activity. Overweight and obesity were considered following

74 World Health Organization recommendations: BMI $25-30 \mathrm{~kg} / \mathrm{m}^{2}$ and $\geq 30 \mathrm{~kg} / \mathrm{m}^{2}$,

75 respectively. Nutrient deficiency was noted for total proteins, total cholesterol,

76 triglycerides, homocysteine-related markers (folic acid and B12 vitamin), iron profile

77 (serum iron, ferritin), and altered values of thyroid-stimulating hormone, ionogram

78 (sodium, potassium), and renal profile (creatinine, urea and glomerular filtration rate

79 from the equation developed by the Modification of Diet in Renal Diseases Study).

80 Diagnostic criteria for cachexia (wasting disease) in adults were applied. These

81 included weight loss of at least 5\% in previous 12 months or less, in the presence of

82 underlying illness and three of the following criteria: decreased muscle strength, fatigue

83 (defined as physical and/or mental weariness resulting from exertion), anorexia (total

84 caloric intake $<20 \mathrm{kcal} / \mathrm{kg}$ body weight/day or $<70 \%$ of usual food intake), low FFMI,

85 or abnormal biochemistry (hemoglobin $<12 \mathrm{~g} / \mathrm{dl}$ or low serum albumin $<3.2 \mathrm{~g} / \mathrm{dl}$ ) (26).

\section{Outcome variables}

87 Main outcome variables were functional status assessed by Barthel index,

88 institutionalization, readmissions, and mortality. Functional status was recorded after

89 discharge by an investigator blinded to the study, obtained by telephone interview with

90 the patient or caregiver. Institutionalization, readmissions, and mortality were collected

91 from caregiver telephone interview and medical records at 3-month follow-up. After

92 follow-up was completed, survival was assessed annually for the whole cohort in the

93 same way. Data on sex, age, comorbidity (Charlson index), cognitive status (Short 
94 Portable Mental Status Questionnaire) (27), and instrumental activities of daily living 95 (Lawton index) were obtained from medical records.

\section{Ethics}

97 National and international research ethics guidelines were followed (28), including the 98 Deontological Code of Ethics, Declaration of Helsinki, and Spain's confidentiality law 99 concerning personal data (Ley Orgánica 15/1999, 13 December, Protección de Datos de 100 Carácter Personal). Written informed consent to participate was signed by all 101 participants and the study was approved by the local Clinical Ethics Committee.

\section{Statistical analysis}

103 Descriptive analysis of the sample used percentages with frequency distributions for 104 categorical variables and means with standard deviation for quantitative continuous 105 variables. Univariate analysis was used to check clinical and functional characteristics 106 of the study participants according to the diagnosis of malnutrition as defined by 107 ESPEN consensus. Qualitative variables were compared by Chi-square or Fisher exact 108 test, as appropriate and quantitative variables by Student $t$ test. As histograms and Q-Q 109 plot showed that Barthel Index at 3 months was not normally distributed, median 110 regression was applied to check median differences (MD) with 95\% confidence interval

111 (CI). The analysis of factors associated with institutionalization was performed using 112 binary logistic regression. These associations were expressed by odds ratios (OR). 113 Associations with post-discharge readmissions and mortality were evaluated by Cox 114 regression. Kaplan-Meier curves for readmissions and for mortality, by malnutrition, 115 were compared using the corresponding log-rank test at 3-month follow-up. Univariate 
116 and multivariate analyses were performed for all outcomes to examine possible 117 associations with covariables. Furthermore, the proportional hazards assumption was 118 checked for each Cox model; there was no evidence of any violation from proportional 119 hazards. P-values $<0.05$ were considered significant. Statistical analysis was performed 120 using R for Windows (V.3.1.3). 


\section{RESULTS}

122 Of 102 eligible patients discharged from the unit during the study period, 95 met

123 inclusion criteria (mean age 84.5 (SD 6.5) years, 63.2\% women). Of the $31(32.6 \%)$

124 patients with unintentional weight loss, 19 (20\%) fulfilled the criteria for a diagnosis of 125 malnutrition as defined by the ESPEN consensus. Nutrition-related conditions were 126 frequent: 94 (99\%) patients met Fried criteria for frailty, $44(46.3 \%)$ for sarcopenia, 58 $127(61.1 \%)$ for overweight/obesity, 59 (62.1\%) had nutrient deficiency, and $20(21.1 \%)$ 128 patients had cachexia. Clinical and functional characteristics of the study participants 129 during their stay in the postacute care unit and at 3-month follow-up are detailed in

130 Table 1. Post-discharge clinical outcomes in patients with malnutrition and other 131 nutrition-related conditions are described in Table 2.

132 Tables 3 to 6 show univariate and multivariate analysis according to clinical outcomes 133 (Barthel index, institutionalization, readmissions, and mortality) at 3-month follow-up. 134 Sarcopenia was the only nutrition-related syndrome that affected Barthel index at 3135 month follow-up, both in univariate analysis (median difference $[\mathrm{MD}]=-25 ; 95 \% \mathrm{CI}$ : 13643.2 to $-6.8 ; \mathrm{p}=0.008)$ and in multivariate analysis $(\mathrm{MD}=-25.5 ; 95 \% \mathrm{CI}:-46.6$ to -4.3 ; $137 \mathrm{p}=0.019)($ Table 3).

138 As shown in Table 4, age and sex showed a significant association with 139 institutionalization in the multivariate analysis. Institutionalization was also related to 140 unintentional weight loss in univariate analysis $(\mathrm{OR}=3.9 ; 95 \% \mathrm{CI}: 1.3$ to $12.4 ; \mathrm{p}=0.018)$ 141 and showed a strong trend in multivariate analysis $(\mathrm{OR}=5.5 ; 95 \% \mathrm{CI}: 0.9$ to 31.6 ; $\mathrm{p}=$ 142 0.058). Similarly, malnutrition was significantly associated with institutionalization in 
143 univariate analysis $(\mathrm{OR}=3.4 ; 95 \% \mathrm{CI}: 1.0$ to $11.3 ; \mathrm{p}=0.042)$, but the association was

144 not maintained under multivariate analysis.

145 At 3-month follow-up, 18 patients had been readmitted; there were no differences in 146 readmissions by clinical characteristics, malnutrition, and other nutrition-related 147 conditions $(\mathrm{p}>0.05)$ (Table 5). Readmissions also did not differ by malnutrition as 148 defined by the ESPEN consensus (log rank p-value=0.685), as shown in Figure 1.

149 Finally, neither malnutrition nor nutrition-related conditions were related to any 150 differences in mortality in the analysis performed (Table 6). Age and comorbidity were 151 the only variables affecting mortality under multivariate analysis. The Kaplan-Meier 152 curve showed no differences in mortality by malnutrition diagnosis, as defined by the 153 ESPEN consensus (log rank p-value=0.533) (Figure 2). 


\section{DISCUSSION}

155 This cohort study assessed the association of malnutrition and nutrition-related

156 conditions with clinical outcomes in older patients at 3 months postdischarge from a 157 postacute care unit. We found that applying malnutrition criteria as defined by the 158 ESPEN consensus had no additional value in predicting poor mid-term outcomes in the 159 studied sample of geriatric patients. Instead, unintentional weight loss (i.e., one of the 160 subscores of the consensus definition) was associated with an increased likelihood of 161 postdischarge institutionalization, and sarcopenia was associated with poorer functional 162 status at 3-month follow-up.

163 The prognostic value of malnutrition as defined by the recently published ESPEN 164 consensus and guidelines has not been explored thoroughly. To the authors' knowledge, 165 the only study reporting an association between malnutrition as defined by the ESPEN 166 consensus and clinical outcomes was carried out in an acute care setting and was limited 167 to analyzing the length of hospital stay (13). Nutrition disorders diagnosed by ESPEN 168 consensus and guidelines are associated with worse functional prognosis during 169 postacute rehabilitation care (15), but there were no studies on this association after 170 discharge. Data from our study showed that the association between malnutrition and 171 functional status did not persist at 3 months postdischarge, a result that was unexpected.

172 A likely explanation for malnutrition's lack of predictive value for post-discharge 173 clinical outcomes is that nutritional deficiencies were correctly addressed during 174 hospitalization, and the expected poor outcomes due to the presence of malnutrition 
175 were effectively cancelled in these patients after the multidisciplinary intervention

176 performed as part of usual post-discharge therapy.

177 Unlike malnutrition as defined by the ESPEN consensus, malnutrition-related

178 syndromes such as sarcopenia or frailty seem to have a negative impact on functional 179 status and rehabilitation outcomes in various settings, including postacute care 180 (22)(29)(30)(31). This observation held true for the present sample, in which the 181 presence of sarcopenia was associated with a lower score on the Barthel index after 3 182 months (14).

183 Unintentional weight loss was related to institutionalization. In a previous study, 184 unintentional weight loss was also related to worse clinical outcomes during hospital 185 stay (poor functional rehabilitation outcomes and longer length of stay) (15). Other 186 studies have considered weight loss prior to admission the most powerful predictor of 187 poor functional outcomes (32) and frailty (33). Unintentional weight loss has been 188 proposed as a key indicator to assess formal nutrition because of its validity, feasibility, 189 efficiency, and availability for every population and level of healthcare assistance (34). 190 Given that unintentional weight loss is a strong predictor of negative outcomes 191 (1)(33)(35)(36), objective anthropometric measurements (weight and height) should be 192 registered in the medical record in order to detect eventual weight loss in patients' 193 follow-up as part of the comprehensive geriatric assessment (37). This factor appears to 194 be an accessible, feasible and low-cost indicator of malnutrition itself in older adults $195(33)(37)(38)(39)$. In the process of creating a consensus on malnutrition diagnostic 196 criteria, now being developed by the Global Leadership Initiative on Malnutrition 
197 (GLIM) (34)(40), it would be desirable that unintentional weight loss be included as a 198 part of this universal tool, suitable for older people.

199 The key point of malnutrition and malnutrition-related syndromes that has aroused great 200 interest for the scientific community is their reversibility, when properly identified and 201 managed. In the therapeutic approach to malnutrition, frailty, and sarcopenia, the most 202 effective strategies to prevent and treat malnutrition and nutrition disorders seem to be 203 an adequate nutrient intake, nutritional supplementation, and physical exercise $204 \quad(29)(41)(42)(43)$.

205 Some limitations may have influenced the results of our study. The criteria for 206 admission to the postacute short-term rehabilitation program constitute an initial 207 selection bias for studies conducted in rehabilitation settings: patients with good initial 208 recovery in the acute care ward as well as those whose physical, cognitive, or functional 209 status prevents them from following a rehabilitation program are excluded. In addition, 210 patients who require a rehabilitation program longer than two weeks are usually sent to 211 other intermediate care settings (14)(22). Therefore, the population is narrowly selected, 212 by definition. It is not surprising that frailty and risk of malnutrition were present in all 213 the sample, given that functional loss resulting from an acute recent process is one of 214 the admission criteria in the postacute care unit. The MNA-SF has been validated for 215 use in Spanish translation and has been recommended as a screening tool by the Spanish 216 Geriatrics and Gerontology Society (20), but the use of the full MNA questionnaire 217 might have improved specificity. On the other hand, malnutrition as defined by the 218 ESPEN consensus is partially based on anthropometric measurements, such as height, 
219 which can be challenging in patients who are unable to stand (12 patients, $13.6 \%$ ) and

220 require the substitution of knee height; furthermore, height measurement does not take

221 into account possible kyphosis or vertebral osteoporotic degenerative changes (44).

222 These factors might interfere with the accuracy of BMI, FFMI, basic definition of

223 malnutrition, and sarcopenia or cachexia diagnosis. Finally, the relatively small sample

224 size and the overlap between malnutrition and its related conditions should also be

225 considered a potential study limitation.

226 The diagnostic criteria proposed by the Academy of Nutrition and Dietetics and 227 American Society for Parenteral and Enteral Nutrition (AND/ASPEN) have also been 228 shown to be a reliable tool in the assessment of malnutrition. Both ASPEN/AND and 229 ESPEN criteria have their pros and cons. The categories of malnutrition and the 230 approach to distinguishing the malnutrition context (acute illness or injury, chronic 231 illness, and social or environmental circumstances) are strong points of the 232 ASPEN/AND criteria; however, this is a complex tool using subjective assessment 233 skills rather than objective body composition measures (45). Conversely, the ESPEN 234 consensus definition is based on objective anthropometric measurements (BMI and 235 FFMI), but some of them have limited availability in clinical settings and are overly 236 restrictive. Further research is required in order to achieve a unified consensus suitable 237 to all populations and settings worldwide (1)(40)(46)(47).

\section{Conclusions}

239 Malnutrition as defined by the ESPEN consensus could not predict functional status, 240 institutionalization, readmissions, and mortality at 3 months after discharge from a 
1

2

3

4

5

6

7

8

9

10

11

12

13

14

15

16

17

18

241 postacute care unit. In contrast, unintentional weight loss, i.e. one of the subscores of

242 the consensus definition, was associated with an increased likelihood of postdischarge

243 institutionalization, and sarcopenia was associated with poorer functional status at 3-

244 month follow-up. Further research with larger samples, multicenter cohorts, and more

245 extended follow-up is required to clarify the clinical value of diagnosing malnutrition

246 using the ESPEN consensus and its ability to predict long-term adverse clinical 247 outcomes. 
249

250

251

252

253

254

255

256

257

258

259

260

261

262

263

264

265

266

267

268

269

270

271

272

273

274

275

276

277

\section{Acknowledgements}

The authors gratefully acknowledge Elaine Lilly, $\mathrm{PhD}$, for unfailing support, language revisions, and suggestions, and librarian Núria Crumols Pey for providing excellent support to researchers.

\section{Conflict of interest}

All authors declare they do not have any financial and personal relationships with other people or organizations that could inappropriately influence their work.

\section{Funding}

No internal or external funding was received to support this research.

\section{REFERENCES}

1. Cederholm T, Bosaeus I, Barazzoni R, Bauer J, Van Gossum A, Klek S, et al. Diagnostic criteria for malnutrition - An ESPEN Consensus Statement. Clin Nutr. 2015 Jun;34(3):335-40.

2. Cederholm T, Barazzoni R, Austin P, Ballmer P, Biolo G, Bischoff SC, et al. ESPEN guidelines on definitions and terminology of clinical nutrition. Clin Nutr. 2017 Feb;36(1):49-64.

3. Morley JE. Novel Approaches to Nutrition in Older Persons. Preface. Clin Geriatr Med. 2015 Aug;31(3):xiii - xiv.

4. Carlsson M, Haglin L, Rosendahl E, Gustafson Y. Poor nutritional status is associated with urinary tract infection among older people living in residential care facilities. J Nutr Health Aging. 2013 Feb 27;17(2):186-91.

5. Phillips SM, Dickerson RN, Moore FA, Paddon-Jones D, Weijs PJM. Protein Turnover and Metabolism in the Elderly Intensive Care Unit Patient. Nutr Clin Pract. 2017 Apr;32(1_suppl):112S - 120S.

6. Wakabayashi H, Sashika H. Malnutrition is associated with poor rehabilitation outcome in elderly inpatients with hospital-associated deconditioning a prospective cohort study. J Rehabil Med. 2014 Mar;46(3):277-82.

7. Rasheed S, Woods RT. Malnutrition and quality of life in older people: A 
systematic review and meta-analysis. Ageing Research Reviews. 2013. p. 561-6.

8. Agarwal E, Ferguson M, Banks M, Batterham M, Bauer J, Capra S, et al.

Malnutrition and poor food intake are associated with prolonged hospital stay, frequent readmissions, and greater in-hospital mortality: results from the Nutrition Care Day Survey 2010. Clin Nutr. 2013 Oct;32(5):737-45.

9. Cerri AP, Bellelli G, Mazzone A, Pittella F, Landi F, Zambon A, et al. Sarcopenia and malnutrition in acutely ill hospitalized elderly: Prevalence and outcomes. Clin Nutr. Churchill Livingstone; 2015 Aug;34(4):745-51.

10. Landi F, Calvani R, Tosato M, Martone AM, Ortolani E, Savera G, et al. Anorexia of Aging: Risk Factors, Consequences, and Potential Treatments. Nutrients. 2016 Jan 27;8(2):69.

11. Jiang J, Hu X, Chen J, Wang H, Zhang L, Dong B, et al. Predicting long-term mortality in hospitalized elderly patients using the new ESPEN definition. Sci Rep. 2017 Dec 22;7(1):4067.

12. Rojer AGM, Kruizenga HM, Trappenburg MC, Reijnierse EM, Sipilä S, Narici M $\mathrm{V}$, et al. The prevalence of malnutrition according to the new ESPEN definition in four diverse populations. Clin Nutr. 2016 Jun 20;35(3):758-62.

13. Sanz-París A, Gómez-Candela C, Martín-Palmero Á, García-Almeida JM, Burgos-Pelaez R, Matía-Martin P, et al. Application of the new ESPEN definition of malnutrition in geriatric diabetic patients during hospitalization: A multicentric study. Clin Nutr. 2016 Dec 8;35(6):1564-7.

14. Sánchez-Rodríguez D, Marco E, Ronquillo-Moreno N, Miralles R, Vázquez-Ibar $\mathrm{O}$, Escalada F, et al. Prevalence of malnutrition and sarcopenia in a post-acute care geriatric unit: Applying the new ESPEN definition and EWGSOP criteria. Clin Nutr. 2016 Sep 9;36(5):1339-44.

15. Sánchez-Rodríguez D, Marco E, Annweiler C, Ronquillo-Moreno N, Tortosa A, Vázquez-Ibar O, et al. Malnutrition in postacute geriatric care: Basic ESPEN diagnosis and etiology based diagnoses analyzed by length of stay, in-hospital mortality, and functional rehabilitation indexes. Arch Gerontol Geriatr. 2017;73:169-76.

16. Cruz-Jentoft AJ, Kiesswetter E, Drey M, Sieber CC. Nutrition, frailty, and sarcopenia. Aging Clin Exp Res. 2017 Feb 2;29(1):43-8.

17. Wakabayashi H, Sakuma K. Rehabilitation nutrition for sarcopenia with disability: a combination of both rehabilitation and nutrition care management. J Cachexia Sarcopenia Muscle. 2014 Dec;5(4):269-77.

18. von Elm E, Altman DG, Egger M, Pocock SJ, Gøtzsche PC, Vandenbroucke JP. The Strengthening the Reporting of Observational Studies in Epidemiology (STROBE) statement: guidelines for reporting observational studies. Lancet. 2007 Oct 20;370(9596):1453-7.

19. Kaiser MJ, Bauer JM, Ramsch C, Uter W, Guigoz Y, Cederholm T, et al. Validation of the Mini Nutritional Assessment short-form (MNA-SF): a practical tool for identification of nutritional status. J Nutr Health Aging. 2009 Nov;13(9):782-8.

20. Camina-Martín MA, de Mateo-Silleras B, Malafarina V, Lopez-Mongil R, NiñoMartín V, López-Trigo JA, et al. Nutritional status assessment in geriatrics: 
Consensus declaration by the Spanish society of geriatrics and gerontology nutrition work group. Maturitas. $2015 \mathrm{Jul} ; 81(3): 414-9$.

21. Chumlea WC, Roche AF, Steinbaugh ML. Estimating stature from knee height for persons 60 to 90 years of age. J Am Geriatr Soc. 1985 Feb;33(2):116-20.

22. Sánchez-Rodríguez D, Marco E, Miralles R, Fayos M, Mojal S, Alvarado M, et al. Sarcopenia, physical rehabilitation and functional outcomes of patients in a subacute geriatric care unit. Arch Gerontol Geriatr. 2014 Jan;59(1):39-43.

23. Schutz Y, Kyle UUG, Pichard C. Fat-free mass index and fat mass index percentiles in Caucasians aged 18-98 y. Int J Obes Relat Metab Disord. 2002 Jul;26(7):953-60.

24. Cruz-Jentoft AJ, Baeyens JP, Bauer JM, Boirie Y, Cederholm T, Landi F, et al. Sarcopenia: European consensus on definition and diagnosis. Age Ageing. 2010;39(April):412-23.

25. Fried LP, Tangen CM, Walston J, Newman AB, Hirsch C, Gottdiener J, et al. Frailty in older adults: evidence for a phenotype. J Gerontol A Biol Sci Med Sci. 2001 Mar;56(3):M146-56.

26. Evans WJ, Morley JE, Argilés J, Bales C, Baracos V, Guttridge D, et al. Cachexia: A new definition. Clin Nutr. 2008 Dec;27(6):793-9.

27. Pfeiffer E. A short portable mental status questionnaire for the assessment of organic brain deficit in elderly patients. J Am Geriatr Soc. 1975 Oct;23(10):43341.

28. Muller MJ, Soares M. The ethics of research publication. Eur J Clin Nutr. 2017 May;71(5):569.

29. Litchford MD. Counteracting the Trajectory of Frailty and Sarcopenia in Older Adults. Nutr Clin Pract. 2014 Aug 9;29(4):428-34.

30. Morley JE. Nutritional supplementation and sarcopenia: the evidence grows. J Am Med Dir Assoc. 2015 Sep 1;16(9):717-9.

31. Landi F, Bernabei R, Russo A, ZuccalÃ G, Onder G, Carosella L, et al. Predictors of Rehabilitation Outcomes in Frail Patients Treated in a Geriatric Hospital. J Am Geriatr Soc. 2002 Apr;50(4):679-84.

32. Lee L-C, Tsai AC. Mini-Nutritional-Assessment (MNA) without body mass index (BMI) predicts functional disability in elderly Taiwanese. Arch Gerontol Geriatr. 2012 May;54(3):e405-10.

33. Fougère B, Morley JE. Editorial: Weight Loss is a Major Cause of Frailty. J Nutr Health Aging. 2017 Nov 22;21(9):933-5.

34. Jensen GL, Cederholm T. Global Leadership Initiative on Malnutrition: Progress Report From ASPEN Clinical Nutrition Week 2017. JPEN J Parenter Enteral Nutr. 2017 Apr 1;148607117707761.

35. Wirth R, Streicher M, Smoliner C, Kolb C, Hiesmayr M, Thiem U, et al. The impact of weight loss and low BMI on mortality of nursing home residents -

Results from the nutritionDay in nursing homes. Clin Nutr. 2016 Aug 19;35(4):900-6.

36. Cheng FW, Gao X, Jensen GL. Weight Change and All-Cause Mortality in Older Adults: A Meta-Analysis. J Nutr Gerontol Geriatr. 2015 Oct 2;34(4):343-68.

37. DiMaria-Ghalili RA. Integrating Nutrition in the Comprehensive Geriatric 
Assessment. Nutr Clin Pract. 2014 Aug 2;29(4):420-7.

38. Russell MK. Functional assessment of nutrition status. Nutr Clin Pract. 2015 Apr $13 ; 30(2): 211-8$.

39. Wijnhoven HAH, van Zon SKR, Twisk J, Visser M. Attribution of causes of weight loss and weight gain to 3-year mortality in older adults: results from the Longitudinal Aging Study Amsterdam. J Gerontol A Biol Sci Med Sci. 2014 Oct 1;69(10):1236-43.

40. Cederholm T, Jensen GL. To create a consensus on malnutrition diagnostic criteria: A report from the Global Leadership Initiative on Malnutrition (GLIM) meeting at the ESPEN Congress 2016. Clin Nutr. 2017 Feb;36(1):7-10.

41. Deutz NEP, Bauer JMJM, Barazzoni R, Biolo G, Boirie Y, Bosy-Westphal A, et al. Protein intake and exercise for optimal muscle function with aging: recommendations from the ESPEN Expert Group. Clin Nutr. 2014 Dec;33(6):929-36.

42. de van der Schueren MAE, Wijnhoven HAH, Kruizenga HM, Visser M. A critical appraisal of nutritional intervention studies in malnourished, community dwelling older persons. Clin Nutr. 2016 Oct;35(5):1008-14.

43. Cruz-Jentoft AJ, Landi F, Schneider SM, Zúñiga C, Arai H, Boirie Y, et al. Prevalence of and interventions for sarcopenia in ageing adults: a systematic review. Report of the International Sarcopenia Initiative (EWGSOP and IWGS). Age Ageing. 2014 Nov;43(6):748-59.

44. Gavriilidou NN, Pihlsgård M, Elmståhl S. High degree of BMI misclassification of malnutrition among Swedish elderly population: Age-adjusted height estimation using knee height and demispan. Eur J Clin Nutr. 2015 May;69(5):565-71.

45. Hand RK, Murphy WJ, Field LB, Lee JA, Parrott JS, Ferguson M, et al. Validation of the Academy/A.S.P.E.N. Malnutrition Clinical Characteristics. J Acad Nutr Diet. 2016 May;116(5):856-64.

46. Cederholm T, Jensen GL. To Create a Consensus on Malnutrition Diagnostic Criteria. JPEN J Parenter Enteral Nutr. 2017 Mar 17;41(3):311-4.

47. White J V., Guenter P, Jensen G, Malone A, Schofield M, Academy Malnutrition Work Group, et al. Consensus Statement: Academy of Nutrition and Dietetics and American Society for Parenteral and Enteral Nutrition: Characteristics Recommended for the Identification and Documentation of Adult Malnutrition (Undernutrition). J Parenter Enter Nutr. 2012 May 1;36(3):275-83. 


\section{INTRODUCTION}

5 Malnutrition is associated with poor functional status and increased mortality in older 6 people (1)(2)(3). The main consequences of malnutrition and its related syndromes, 7 such as frailty or sarcopenia, include increased risks of infections (4)(5), loss of 8 independence (6), worsening health-related quality of life (7), and death (8)(9)(10)(11).

9 Given the lack of consensual malnutrition guidelines, the European Society for Clinical 10 Nutrition and Metabolism (ESPEN) recently made an effort to establish a definition of 11 malnutrition that would be applicable in all adult age-ranges and healthcare settings, 12 independent of etiology (1). The ESPEN consensus definition of malnutrition guidelines 13 on definition and diagnoses has provided clinicians and researchers a practical tool for 14 the hierarchical organization of nutrition disorders, nutrition-related conditions, and 15 nutrition-related syndromes (2).

16 The ESPEN consensus definition of malnutrition has been applied in both acute $17(11)(12)(13)$ and postacute care (14)(15). In a large population of hospitalized older 18 patients with diabetes, malnutrition lengthened the hospital stay, increased the 19 probability of in-hospital death by a factor of 2.7 , and decreased the probability of being 20 discharged home rather than to an institution (13). Early management of nutrition 21 disorders and nutrition-related conditions (1), once detected, could improve the life 22 course of patients (16)(17). 
1

2

3

4

5

6

7

8

9

10

11

12

13

14

15

16

17

18

19

20

21

22

23

24

25

26

27

28

29

30

31

32

33

34

35

36

37

38

39

40

41

42

43

44

45

46

47

48

49

50

51

52

53

54

55

56

57

58

59

60

23 The objective of this longitudinal study was to determine whether the malnutrition and

24 nutrition-related conditions diagnosed during hospitalization using the ESPEN

25 consensus definition were associated with post-discharge clinical outcomes (functional

26 status assessed by Barthel index, institutionalization, hospital readmissions, and

27 mortality) among older patients at 3-month follow-up. 


\section{METHODS}

\section{Design}

30 Cohort study of postacute inpatients who participated in a larger prospective study on

31 malnutrition and sarcopenia (14). The Strengthening the Reporting of Observational

32 Studies in Epidemiology (STROBE) Statement (18) was followed (Additional file 1).

\section{Setting}

34 The study was conducted in a postacute geriatric rehabilitation care unit in a university 35 hospital. The unit focuses specifically on a 2-week period of rehabilitation and 36 functional recovery, after which patients are expected to be discharged home.

\section{Participants}

38 Consecutive patients aged $\geq 70$ years hospitalized in the postacute geriatric rehabilitation 39 care unit due to functional loss resulting from a non-disabling medical disease were 40 included from January to August 2011. Patients with general and/or cognitive conditions 41 (Mini-Mental State Examination score <21/30) that prevented completion of the 42 diagnostic tests or absence of information regarding weight loss in the previous year 43 were excluded.

\section{$44 \quad$ Procedure}

45 All inpatients were screened for risk of malnutrition at admission by the Mini46 Nutritional Assessment Short-Form (MNA-SF) (19)(20). The diagnosis of malnutrition 47 as defined by the ESPEN consensus was then retrospectively applied in all patients 48 identified as at risk of malnutrition (MNA-SF scores $\leq 11$ ). The ESPEN definition pro- 
49 poses two alternative ways to diagnose malnutrition: body mass index (BMI) $<18.5$

$50 \mathrm{~kg} / \mathrm{m}^{2}$ (alternative 1) or unintentional weight loss ( $>10 \%$ indefinite of time, or $>5 \%$ over

51 the last 3 months) combined with age-related BMI (BMI $<20 \mathrm{~kg} / \mathrm{m}^{2}$ in $<70$ years, or $52<22 \mathrm{~kg} / \mathrm{m}^{2}$ in $\geq 70$ years $)$ or fat-free mass index $\left(<17 \mathrm{~kg} / \mathrm{m}^{2}\right.$ in men and $15 \mathrm{~kg} / \mathrm{m}^{2}$ in

53 women) (1). Unintentional weight loss was obtained from medical records. If data for

54 the last 3 months were unavailable, weight loss was assessed by patient and caregiver

55 interview or from weight data recorded in the medical record during the last year. BMI

56 was calculated from height and weight $\left(\mathrm{kg} / \mathrm{m}^{2}\right)$ : height was measured in all patients able

57 to stand safely, otherwise a knee height equation (21) was applied; body weight was

58 measured to the nearest $0.1 \mathrm{~kg}$. Fat-free mass (FFM), expressed in $\mathrm{kg}$, was measured

59 by bioimpedance (Bodystat 1500, Bodystat Ltd., Isle of Man British Isles) as previously

60 described (14)(22). The FFM values were divided by height squared to obtain the fat-

61 free mass index (FFMI), expressed in $\mathrm{kg} / \mathrm{m}^{2}$ and compared with those of the reference

62 population (23).

63 Nutrition-related conditions (sarcopenia, frailty, overweight/obesity, and nutrient 64 deficiency) were also considered (1). The term "nutrition-related syndrome" was used to 65 refer to a condition included in the definition, such as sarcopenia and frailty that is also 66 identified as a geriatric syndrome. Sarcopenia was assessed following The European 67 Working Group on Sarcopenia in Older People (EWGSOP) criteria: low muscle mass in presence of low muscle function or low physical performance (24) assessed with

69 bioimpedance analysis, isometric handgrip dynamometry, and gait speed in a 4-m walk

70 test as previously described (14)(22). Gait speed was considered $0 \mathrm{~m} / \mathrm{s}$ in bedridden

71 patients unable to stand. Frailty was assessed by the Frailty Phenotype (25) in presence 
72 of three of the following criteria: weight loss, weakness, exhaustion, slow walking

73 speed, and low physical activity. Overweight and obesity were considered following

74 World Health Organization recommendations: BMI $25-30 \mathrm{~kg} / \mathrm{m}^{2}$ and $\geq 30 \mathrm{~kg} / \mathrm{m}^{2}$,

75 respectively. Nutrient deficiency was noted for total proteins, total cholesterol,

76 triglycerides, homocysteine-related markers (folic acid and B12 vitamin), iron profile

77 (serum iron, ferritin), and altered values of thyroid-stimulating hormone, ionogram

78 (sodium, potassium), and renal profile (creatinine, urea and glomerular filtration rate

79 from the equation developed by the Modification of Diet in Renal Diseases Study).

80 Diagnostic criteria for cachexia (wasting disease) in adults were applied. These

81 included weight loss of at least 5\% in previous 12 months or less, in the presence of

82 underlying illness and three of the following criteria: decreased muscle strength, fatigue

83 (defined as physical and/or mental weariness resulting from exertion), anorexia (total

84 caloric intake $<20 \mathrm{kcal} / \mathrm{kg}$ body weight/day or $<70 \%$ of usual food intake), low FFMI,

85 or abnormal biochemistry (hemoglobin $<12 \mathrm{~g} / \mathrm{dl}$ or low serum albumin $<3.2 \mathrm{~g} / \mathrm{dl}$ ) (26).

\section{Outcome variables}

87 Main outcome variables were functional status assessed by Barthel index,

88 institutionalization, readmissions, and mortality. Functional status was recorded after

89 discharge by an investigator blinded to the study, obtained by telephone interview with

90 the patient or caregiver. Institutionalization, readmissions, and mortality were collected

91 from caregiver telephone interview and medical records at 3-month follow-up. After

92 follow-up was completed, survival was assessed annually for the whole cohort in the

93 same way. Data on sex, age, comorbidity (Charlson index), cognitive status (Short 
94 Portable Mental Status Questionnaire) (27), and instrumental activities of daily living 95 (Lawton index) were obtained from medical records.

\section{Ethics}

97 National and international research ethics guidelines were followed (28), including the 98 Deontological Code of Ethics, Declaration of Helsinki, and Spain's confidentiality law 99 concerning personal data (Ley Orgánica 15/1999, 13 December, Protección de Datos de 100 Carácter Personal). Written informed consent to participate was signed by all 101 participants and the study was approved by the local Clinical Ethics Committee.

\section{Statistical analysis}

103 Descriptive analysis of the sample used percentages with frequency distributions for 104 categorical variables and means with standard deviation for quantitative continuous 105 variables. Univariate analysis was used to check clinical and functional characteristics 106 of the study participants according to the diagnosis of malnutrition as defined by 107 ESPEN consensus. Qualitative variables were compared by Chi-square or Fisher exact 108 test, as appropriate and quantitative variables by Student $t$ test. As histograms and Q-Q 109 plot showed that Barthel Index at 3 months was not normally distributed, median 110 regression was applied to check median differences (MD) with 95\% confidence interval

111 (CI). The analysis of factors associated with institutionalization was performed using 112 binary logistic regression. These associations were expressed by odds ratios (OR). 113 Associations with post-discharge readmissions and mortality were evaluated by Cox 114 regression. Kaplan-Meier curves for readmissions and for mortality, by malnutrition, 115 were compared using the corresponding log-rank test at 3-month follow-up. Univariate 
116 and multivariate analyses were performed for all outcomes to examine possible 117 associations with covariables. Furthermore, the proportional hazards assumption was 118 checked for each Cox model; there was no evidence of any violation from proportional 119 hazards. P-values $<0.05$ were considered significant. Statistical analysis was performed 120 using R for Windows (V.3.1.3). 


\section{$121 \quad$ RESULTS}

122 Of 102 eligible patients discharged from the unit during the study period, 95 met 123 inclusion criteria (mean age 84.5 (SD 6.5) years, 63.2\% women). Of the $31(32.6 \%)$ 124 patients with unintentional weight loss, 19 (20\%) fulfilled the criteria for a diagnosis of 125 malnutrition as defined by the ESPEN consensus. Nutrition-related conditions were 126 frequent: 94 (99\%) patients met Fried criteria for frailty, 44 (46.3\%) for sarcopenia, 58 127 (61.1\%) for overweight/obesity, 59 (62.1\%) had nutrient deficiency, and $20(21.1 \%)$ 128 patients had cachexia. Clinical and functional characteristics of the study participants 129 during their stay in the postacute care unit and at 3-month follow-up are detailed in 130 Table 1. Post-discharge clinical outcomes in patients with malnutrition and other 131 nutrition-related conditions are described in Table 2.

132 Tables 3 to 6 show univariate and multivariate analysis according to clinical outcomes 133 (Barthel index, institutionalization, readmissions, and mortality) at 3-month follow-up. 134 Sarcopenia was the only nutrition-related syndrome that affected Barthel index at 3135 month follow-up, both in univariate analysis (median difference $[\mathrm{MD}]=-25 ; 95 \% \mathrm{CI}$ : 13643.2 to $-6.8 ; \mathrm{p}=0.008)$ and in multivariate analysis $(\mathrm{MD}=-25.5 ; 95 \% \mathrm{CI}:-46.6$ to -4.3 ; $137 \mathrm{p}=0.019)($ Table 3).

138 As shown in Table 4, age and sex showed a significant association with 139 institutionalization in the multivariate analysis. Institutionalization was also related to 140 unintentional weight loss in univariate analysis ( $\mathrm{OR}=3.9 ; 95 \% \mathrm{CI}: 1.3$ to $12.4 ; \mathrm{p}=0.018)$ 141 and showed a strong trend in multivariate analysis $(\mathrm{OR}=5.5 ; 95 \% \mathrm{CI}: 0.9$ to 31.6 ; $\mathrm{p}=$ 142 0.058). Similarly, malnutrition was significantly associated with institutionalization in 
143 univariate analysis $(\mathrm{OR}=3.4 ; 95 \% \mathrm{CI}: 1.0$ to $11.3 ; \mathrm{p}=0.042)$, but the association was

144 not maintained under multivariate analysis.

145 At 3-month follow-up, 18 patients had been readmitted; there were no differences in 146 readmissions by clinical characteristics, malnutrition, and other nutrition-related 147 conditions $(\mathrm{p}>0.05)$ (Table 5). Readmissions also did not differ by malnutrition as 148 defined by the ESPEN consensus (log rank p-value=0.685), as shown in Figure 1.

149 Finally, neither malnutrition nor nutrition-related conditions were related to any 150 differences in mortality in the analysis performed (Table 6). Age and comorbidity were 151 the only variables affecting mortality under multivariate analysis. The Kaplan-Meier 152 curve showed no differences in mortality by malnutrition diagnosis, as defined by the 153 ESPEN consensus (log rank p-value=0.533) (Figure 2). 


\section{DISCUSSION}

155 This cohort study assessed the association of malnutrition and nutrition-related

156 conditions with clinical outcomes in older patients at 3 months postdischarge from a

157 postacute care unit. We found that applying malnutrition criteria as defined by the 158 ESPEN consensus had no additional value in predicting poor mid-term outcomes in the 159 studied sample of geriatric patients. Instead, unintentional weight loss (i.e., one of the 160 subscores of the consensus definition) was associated with an increased likelihood of 161 postdischarge institutionalization, and sarcopenia was associated with poorer functional 162 status at 3-month follow-up.

163 The prognostic value of malnutrition as defined by the recently published ESPEN 164 consensus and guidelines has not been explored thoroughly. To the authors' knowledge, 165 the only study reporting an association between malnutrition as defined by the ESPEN 166 consensus and clinical outcomes was carried out in an acute care setting and was limited 167 to analyzing the length of hospital stay (13). Nutrition disorders diagnosed by ESPEN 168 consensus and guidelines are associated with worse functional prognosis during 169 postacute rehabilitation care (15), but there were no studies on this association after 170 discharge. Data from our study showed that the association between malnutrition and 171 functional status did not persist at 3 months postdischarge, a result that was unexpected.

172 A likely explanation for malnutrition's lack of predictive value for post-discharge 173 clinical outcomes is that nutritional deficiencies were correctly addressed during 174 hospitalization, and the expected poor outcomes due to the presence of malnutrition 
175 were effectively cancelled in these patients after the multidisciplinary intervention

176 performed as part of usual post-discharge therapy.

177 Unlike malnutrition as defined by the ESPEN consensus, malnutrition-related

178 syndromes such as sarcopenia or frailty seem to have a negative impact on functional 179 status and rehabilitation outcomes in various settings, including postacute care 180 (22)(29)(30)(31). This observation held true for the present sample, in which the 181 presence of sarcopenia was associated with a lower score on the Barthel index after 3 182 months (14).

183 Unintentional weight loss was related to institutionalization. In a previous study, 184 unintentional weight loss was also related to worse clinical outcomes during hospital 185 stay (poor functional rehabilitation outcomes and longer length of stay) (15). Other 186 studies have considered weight loss prior to admission the most powerful predictor of 187 poor functional outcomes (32) and frailty (33). Unintentional weight loss has been 188 proposed as a key indicator to assess formal nutrition because of its validity, feasibility, 189 efficiency, and availability for every population and level of healthcare assistance (34). 190 Given that unintentional weight loss is a strong predictor of negative outcomes 191 (1)(33)(35)(36), objective anthropometric measurements (weight and height) should be 192 registered in the medical record in order to detect eventual weight loss in patients' 193 follow-up as part of the comprehensive geriatric assessment (37). This factor appears to 194 be an accessible, feasible and low-cost indicator of malnutrition itself in older adults $195(33)(37)(38)(39)$. In the process of creating a consensus on malnutrition diagnostic 196 criteria, now being developed by the Global Leadership Initiative on Malnutrition 
197 (GLIM) (34)(40), it would be desirable that unintentional weight loss be included as a 198 part of this universal tool, suitable for older people.

199 The key point of malnutrition and malnutrition-related syndromes that has aroused great 200 interest for the scientific community is their reversibility, when properly identified and 201 managed. In the therapeutic approach to malnutrition, frailty, and sarcopenia, the most 202 effective strategies to prevent and treat malnutrition and nutrition disorders seem to be 203 an adequate nutrient intake, nutritional supplementation, and physical exercise $204 \quad(29)(41)(42)(43)$.

205 Some limitations may have influenced the results of our study. The criteria for 206 admission to the postacute short-term rehabilitation program constitute an initial 207 selection bias for studies conducted in rehabilitation settings: patients with good initial 208 recovery in the acute care ward as well as those whose physical, cognitive, or functional 209 status prevents them from following a rehabilitation program are excluded. In addition, 210 patients who require a rehabilitation program longer than two weeks are usually sent to 211 other intermediate care settings (14)(22). Therefore, the population is narrowly selected, 212 by definition. It is not surprising that frailty and risk of malnutrition were present in all 213 the sample, given that functional loss resulting from an acute recent process is one of 214 the admission criteria in the postacute care unit. The MNA-SF has been validated for 215 use in Spanish translation and has been recommended as a screening tool by the Spanish 216 Geriatrics and Gerontology Society (20), but the use of the full MNA questionnaire 217 might have improved specificity. On the other hand, malnutrition as defined by the 218 ESPEN consensus is partially based on anthropometric measurements, such as height, 
219 which can be challenging in patients who are unable to stand (12 patients, $13.6 \%$ ) and

220 require the substitution of knee height; furthermore, height measurement does not take

221 into account possible kyphosis or vertebral osteoporotic degenerative changes (44).

222 These factors might interfere with the accuracy of BMI, FFMI, basic definition of

223 malnutrition, and sarcopenia or cachexia diagnosis. Finally, the relatively small sample

224 size and the overlap between malnutrition and its related conditions should also be

225 considered a potential study limitation.

226 The diagnostic criteria proposed by the Academy of Nutrition and Dietetics and 227 American Society for Parenteral and Enteral Nutrition (AND/ASPEN) have also been 228 shown to be a reliable tool in the assessment of malnutrition. Both ASPEN/AND and 229 ESPEN criteria have their pros and cons. The categories of malnutrition and the 230 approach to distinguishing the malnutrition context (acute illness or injury, chronic 231 illness, and social or environmental circumstances) are strong points of the 232 ASPEN/AND criteria; however, this is a complex tool using subjective assessment 233 skills rather than objective body composition measures (45). Conversely, the ESPEN 234 consensus definition is based on objective anthropometric measurements (BMI and 235 FFMI), but some of them have limited availability in clinical settings and are overly 236 restrictive. Further research is required in order to achieve a unified consensus suitable 237 to all populations and settings worldwide (1)(40)(46)(47).

\section{Conclusions}

239 Malnutrition as defined by the ESPEN consensus could not predict functional status, 240 institutionalization, readmissions, and mortality at 3 months after discharge from a 
241 postacute care unit. In contrast, unintentional weight loss, i.e. one of the subscores of 242 the consensus definition, was associated with an increased likelihood of postdischarge 243 institutionalization, and sarcopenia was associated with poorer functional status at 3244 month follow-up. Further research with larger samples, multicenter cohorts, and more 245 extended follow-up is required to clarify the clinical value of diagnosing malnutrition 246 using the ESPEN consensus and its ability to predict long-term adverse clinical 247 outcomes. 
249

250

251

252

253

254

255

256

257

258

259

260

261

262

263

264

265

266

267

268

269

270

271

272

273

274

275

276

277

\section{Acknowledgements}

The authors gratefully acknowledge Elaine Lilly, $\mathrm{PhD}$, for unfailing support, language revisions, and suggestions, and librarian Núria Crumols Pey for providing excellent support to researchers.

\section{Conflict of interest}

All authors declare they do not have any financial and personal relationships with other people or organizations that could inappropriately influence their work.

\section{Funding}

No internal or external funding was received to support this research.

\section{REFERENCES}

1. Cederholm T, Bosaeus I, Barazzoni R, Bauer J, Van Gossum A, Klek S, et al. Diagnostic criteria for malnutrition - An ESPEN Consensus Statement. Clin Nutr. 2015 Jun;34(3):335-40.

2. Cederholm T, Barazzoni R, Austin P, Ballmer P, Biolo G, Bischoff SC, et al. ESPEN guidelines on definitions and terminology of clinical nutrition. Clin Nutr. 2017 Feb;36(1):49-64.

3. Morley JE. Novel Approaches to Nutrition in Older Persons. Preface. Clin Geriatr Med. 2015 Aug;31(3):xiii - xiv.

4. Carlsson M, Haglin L, Rosendahl E, Gustafson Y. Poor nutritional status is associated with urinary tract infection among older people living in residential care facilities. J Nutr Health Aging. 2013 Feb 27;17(2):186-91.

5. Phillips SM, Dickerson RN, Moore FA, Paddon-Jones D, Weijs PJM. Protein Turnover and Metabolism in the Elderly Intensive Care Unit Patient. Nutr Clin Pract. 2017 Apr;32(1_suppl):112S - 120S.

6. Wakabayashi H, Sashika H. Malnutrition is associated with poor rehabilitation outcome in elderly inpatients with hospital-associated deconditioning a prospective cohort study. J Rehabil Med. 2014 Mar;46(3):277-82.

7. Rasheed S, Woods RT. Malnutrition and quality of life in older people: A 
systematic review and meta-analysis. Ageing Research Reviews. 2013. p. 561-6.

8. Agarwal E, Ferguson M, Banks M, Batterham M, Bauer J, Capra S, et al. Malnutrition and poor food intake are associated with prolonged hospital stay, frequent readmissions, and greater in-hospital mortality: results from the Nutrition Care Day Survey 2010. Clin Nutr. 2013 Oct;32(5):737-45.

9. Cerri AP, Bellelli G, Mazzone A, Pittella F, Landi F, Zambon A, et al. Sarcopenia and malnutrition in acutely ill hospitalized elderly: Prevalence and outcomes. Clin Nutr. Churchill Livingstone; 2015 Aug;34(4):745-51.

10. Landi F, Calvani R, Tosato M, Martone AM, Ortolani E, Savera G, et al. Anorexia of Aging: Risk Factors, Consequences, and Potential Treatments. Nutrients. 2016 Jan 27;8(2):69.

11. Jiang J, Hu X, Chen J, Wang H, Zhang L, Dong B, et al. Predicting long-term mortality in hospitalized elderly patients using the new ESPEN definition. Sci Rep. 2017 Dec 22;7(1):4067.

12. Rojer AGM, Kruizenga HM, Trappenburg MC, Reijnierse EM, Sipilä S, Narici M $\mathrm{V}$, et al. The prevalence of malnutrition according to the new ESPEN definition in four diverse populations. Clin Nutr. 2016 Jun 20;35(3):758-62.

13. Sanz-París A, Gómez-Candela C, Martín-Palmero Á, García-Almeida JM, Burgos-Pelaez R, Matía-Martin P, et al. Application of the new ESPEN definition of malnutrition in geriatric diabetic patients during hospitalization: A multicentric study. Clin Nutr. 2016 Dec 8;35(6):1564-7.

14. Sánchez-Rodríguez D, Marco E, Ronquillo-Moreno N, Miralles R, Vázquez-Ibar $\mathrm{O}$, Escalada F, et al. Prevalence of malnutrition and sarcopenia in a post-acute care geriatric unit: Applying the new ESPEN definition and EWGSOP criteria. Clin Nutr. 2016 Sep 9;36(5):1339-44.

15. Sánchez-Rodríguez D, Marco E, Annweiler C, Ronquillo-Moreno N, Tortosa A, Vázquez-Ibar O, et al. Malnutrition in postacute geriatric care: Basic ESPEN diagnosis and etiology based diagnoses analyzed by length of stay, in-hospital mortality, and functional rehabilitation indexes. Arch Gerontol Geriatr. 2017;73:169-76.

16. Cruz-Jentoft AJ, Kiesswetter E, Drey M, Sieber CC. Nutrition, frailty, and sarcopenia. Aging Clin Exp Res. 2017 Feb 2;29(1):43-8.

17. Wakabayashi H, Sakuma K. Rehabilitation nutrition for sarcopenia with disability: a combination of both rehabilitation and nutrition care management. J Cachexia Sarcopenia Muscle. 2014 Dec;5(4):269-77.

18. von Elm E, Altman DG, Egger M, Pocock SJ, Gøtzsche PC, Vandenbroucke JP. The Strengthening the Reporting of Observational Studies in Epidemiology (STROBE) statement: guidelines for reporting observational studies. Lancet. 2007 Oct 20;370(9596):1453-7.

19. Kaiser MJ, Bauer JM, Ramsch C, Uter W, Guigoz Y, Cederholm T, et al. Validation of the Mini Nutritional Assessment short-form (MNA-SF): a practical tool for identification of nutritional status. J Nutr Health Aging. 2009 Nov;13(9):782-8.

20. Camina-Martín MA, de Mateo-Silleras B, Malafarina V, Lopez-Mongil R, NiñoMartín V, López-Trigo JA, et al. Nutritional status assessment in geriatrics: 
Consensus declaration by the Spanish society of geriatrics and gerontology nutrition work group. Maturitas. $2015 \mathrm{Jul} ; 81(3): 414-9$.

21. Chumlea WC, Roche AF, Steinbaugh ML. Estimating stature from knee height for persons 60 to 90 years of age. J Am Geriatr Soc. 1985 Feb;33(2):116-20.

22. Sánchez-Rodríguez D, Marco E, Miralles R, Fayos M, Mojal S, Alvarado M, et al. Sarcopenia, physical rehabilitation and functional outcomes of patients in a subacute geriatric care unit. Arch Gerontol Geriatr. 2014 Jan;59(1):39-43.

23. Schutz Y, Kyle UUG, Pichard C. Fat-free mass index and fat mass index percentiles in Caucasians aged 18-98 y. Int J Obes Relat Metab Disord. 2002 Jul;26(7):953-60.

24. Cruz-Jentoft AJ, Baeyens JP, Bauer JM, Boirie Y, Cederholm T, Landi F, et al. Sarcopenia: European consensus on definition and diagnosis. Age Ageing. 2010;39(April):412-23.

25. Fried LP, Tangen CM, Walston J, Newman AB, Hirsch C, Gottdiener J, et al. Frailty in older adults: evidence for a phenotype. J Gerontol A Biol Sci Med Sci. 2001 Mar;56(3):M146-56.

26. Evans WJ, Morley JE, Argilés J, Bales C, Baracos V, Guttridge D, et al. Cachexia: A new definition. Clin Nutr. 2008 Dec;27(6):793-9.

27. Pfeiffer E. A short portable mental status questionnaire for the assessment of organic brain deficit in elderly patients. J Am Geriatr Soc. 1975 Oct;23(10):43341.

28. Muller MJ, Soares M. The ethics of research publication. Eur J Clin Nutr. 2017 May;71(5):569.

29. Litchford MD. Counteracting the Trajectory of Frailty and Sarcopenia in Older Adults. Nutr Clin Pract. 2014 Aug 9;29(4):428-34.

30. Morley JE. Nutritional supplementation and sarcopenia: the evidence grows. J Am Med Dir Assoc. 2015 Sep 1;16(9):717-9.

31. Landi F, Bernabei R, Russo A, ZuccalÃ G, Onder G, Carosella L, et al. Predictors of Rehabilitation Outcomes in Frail Patients Treated in a Geriatric Hospital. J Am Geriatr Soc. 2002 Apr;50(4):679-84.

32. Lee L-C, Tsai AC. Mini-Nutritional-Assessment (MNA) without body mass index (BMI) predicts functional disability in elderly Taiwanese. Arch Gerontol Geriatr. 2012 May;54(3):e405-10.

33. Fougère B, Morley JE. Editorial: Weight Loss is a Major Cause of Frailty. J Nutr Health Aging. 2017 Nov 22;21(9):933-5.

34. Jensen GL, Cederholm T. Global Leadership Initiative on Malnutrition: Progress Report From ASPEN Clinical Nutrition Week 2017. JPEN J Parenter Enteral Nutr. 2017 Apr 1;148607117707761.

35. Wirth R, Streicher M, Smoliner C, Kolb C, Hiesmayr M, Thiem U, et al. The impact of weight loss and low BMI on mortality of nursing home residents -

Results from the nutritionDay in nursing homes. Clin Nutr. 2016 Aug 19;35(4):900-6.

36. Cheng FW, Gao X, Jensen GL. Weight Change and All-Cause Mortality in Older Adults: A Meta-Analysis. J Nutr Gerontol Geriatr. 2015 Oct 2;34(4):343-68.

37. DiMaria-Ghalili RA. Integrating Nutrition in the Comprehensive Geriatric 
Assessment. Nutr Clin Pract. 2014 Aug 2;29(4):420-7.

38. Russell MK. Functional assessment of nutrition status. Nutr Clin Pract. 2015 Apr $13 ; 30(2): 211-8$.

39. Wijnhoven HAH, van Zon SKR, Twisk J, Visser M. Attribution of causes of weight loss and weight gain to 3-year mortality in older adults: results from the Longitudinal Aging Study Amsterdam. J Gerontol A Biol Sci Med Sci. 2014 Oct 1;69(10):1236-43.

40. Cederholm T, Jensen GL. To create a consensus on malnutrition diagnostic criteria: A report from the Global Leadership Initiative on Malnutrition (GLIM) meeting at the ESPEN Congress 2016. Clin Nutr. 2017 Feb;36(1):7-10.

41. Deutz NEP, Bauer JMJM, Barazzoni R, Biolo G, Boirie Y, Bosy-Westphal A, et al. Protein intake and exercise for optimal muscle function with aging: recommendations from the ESPEN Expert Group. Clin Nutr. 2014 Dec;33(6):929-36.

42. de van der Schueren MAE, Wijnhoven HAH, Kruizenga HM, Visser M. A critical appraisal of nutritional intervention studies in malnourished, community dwelling older persons. Clin Nutr. 2016 Oct;35(5):1008-14.

43. Cruz-Jentoft AJ, Landi F, Schneider SM, Zúñiga C, Arai H, Boirie Y, et al. Prevalence of and interventions for sarcopenia in ageing adults: a systematic review. Report of the International Sarcopenia Initiative (EWGSOP and IWGS). Age Ageing. 2014 Nov;43(6):748-59.

44. Gavriilidou NN, Pihlsgård M, Elmståhl S. High degree of BMI misclassification of malnutrition among Swedish elderly population: Age-adjusted height estimation using knee height and demispan. Eur J Clin Nutr. 2015 May;69(5):565-71.

45. Hand RK, Murphy WJ, Field LB, Lee JA, Parrott JS, Ferguson M, et al. Validation of the Academy/A.S.P.E.N. Malnutrition Clinical Characteristics. J Acad Nutr Diet. 2016 May;116(5):856-64.

46. Cederholm T, Jensen GL. To Create a Consensus on Malnutrition Diagnostic Criteria. JPEN J Parenter Enteral Nutr. 2017 Mar 17;41(3):311-4.

47. White J V., Guenter P, Jensen G, Malone A, Schofield M, Academy Malnutrition Work Group, et al. Consensus Statement: Academy of Nutrition and Dietetics and American Society for Parenteral and Enteral Nutrition: Characteristics Recommended for the Identification and Documentation of Adult Malnutrition (Undernutrition). J Parenter Enter Nutr. 2012 May 1;36(3):275-83. 


\section{Highlights}

ESPEN consensus and guidelines were applied in a longitudinal follow-up after being discharged from a postacute geriatric care unit

ESPEN consensus could not identify older patients at risk of readmissions and mortality in older patients discharged from a postacute care unit

Further research with larger samples, multicenter cohorts, and more extended follow-up is required to clarify the clinical value of the ESPEN consensus to predict long-term adverse clinical outcomes.

Further research is needed on the potential prognostic value of the ESPEN consensus guidelines 
Table 1.Clinical and functional characteristics of the study participants according to malnutrition as defined by the ESPEN consensus ( $n=95)$.

\begin{tabular}{|c|c|c|c|c|}
\hline & $\begin{array}{c}\text { Total sample } \\
\quad(n=95)\end{array}$ & $\begin{array}{l}\text { Malnutrition } \\
\qquad(\mathrm{n}=19)\end{array}$ & $\begin{array}{l}\text { No malnutrition } \\
\qquad(n=76)\end{array}$ & $\mathbf{p}$ \\
\hline \multicolumn{5}{|c|}{ Intrahospital variables } \\
\hline Age (years) & $84.5(6.5)$ & $84.3(5.3)$ & $84.6(6.8)$ & 0.479 \\
\hline $\begin{array}{l}\text { Sex: } \\
\begin{aligned} & \\
& \\
\text { - } & \text { Male } \\
& \text { Female }\end{aligned}\end{array}$ & $\begin{array}{l}35(36.8 \%) \\
60(63.2 \%)\end{array}$ & $\begin{array}{c}6(31.6 \%) \\
13(68.4 \%)\end{array}$ & $\begin{array}{l}29(38.2 \%) \\
47(61.8 \%)\end{array}$ & 0.595 \\
\hline Body mass index (BMI, $\left.\mathrm{Kg} / \mathrm{m}^{2}\right)$ & $25.5(4.3)$ & $21.7(4.3)$ & $26.3(3.9)$ & 0.005 \\
\hline Fat-free mass index (FFMI, $\mathrm{Kg} / \mathrm{m}^{2}$ ) & $14.9(2.9)$ & $12.7(1.7)$ & $15.4(2.9)$ & 0.007 \\
\hline Fat-free mass $(\mathrm{Kg})$ & $38.4(10.3)$ & $32.4(6.6)$ & $39.7(10.5)$ & 0.069 \\
\hline Unintentional weight loss & $31(32.6 \%)$ & $14(73.7 \%)$ & $17(22.4 \%)$ & $<0.001$ \\
\hline Charlson comorbidity index & $2.4(1.8)$ & $2.5(2.2)$ & $2.3(1.7)$ & 0.466 \\
\hline Short Portable Mental Status Questionnaire & $4.2(3.1)$ & $5.1(3.4)$ & $4.0(3.0)$ & 0.265 \\
\hline Instrumental activities of daily living & $2.6(2.6)$ & $2.5(2.9)$ & $2.6(2.5)$ & 0.577 \\
\hline $\begin{array}{l}\text { Barthel index: } \\
\begin{aligned} \text { - } & \text { Prior } \\
\text { - } & \text { At admission } \\
\text { - } & \text { At discharge }\end{aligned}\end{array}$ & $\begin{array}{l}71.4(21.6) \\
27.0(15.4) \\
54.3(26.2)\end{array}$ & $\begin{array}{l}66.4(25.3) \\
19.1(14.8) \\
38.9(29.1)\end{array}$ & $\begin{array}{l}72.5(20.8) \\
28.7(15.1) \\
57.7(24.5)\end{array}$ & $\begin{array}{l}0.359 \\
0.057 \\
\mathbf{0 . 0 0 7}\end{array}$ \\
\hline Length of stay in postacute care unit (days) & $14.9(5.8)$ & $18.3(8.1)$ & $14.1(4.9)$ & 0.009 \\
\hline \multicolumn{5}{|c|}{ Postdischarge variables at 3-month follow-up } \\
\hline Barthel index & $48.3(30.6)$ & $36.5(27.7)$ & $51.4(30.7)$ & 0.055 \\
\hline Institutionalization & $15(15.8 \%)$ & $6(47.4 \%)$ & $9(11.8 \%)$ & 0.035 \\
\hline Readmissions & $19(20 \%)$ & $3(15.8 \%)$ & $16(21.1 \%)$ & 0.608 \\
\hline Mortality postdischarge & $13(13.7 \%)$ & $3(15.8 \%)$ & $10(13.2 \%)$ & 0.765 \\
\hline
\end{tabular}

(*) Data are expressed as numbers and percentages for categorical variables, and as mean and standard deviation (SD) for continuous variables. 
Table 2. Post-discharge clinical outcomesaccording to malnutrition and malnutritionrelated syndromes at 3 -month follow-up $(n=95)$.

\begin{tabular}{|l|c|c|c|c|c|}
\hline & $\begin{array}{c}\text { Malnutrition } \\
(\text { ESPEN) } \\
(\mathbf{n = 1 9 )}\end{array}$ & $\begin{array}{c}\text { Sarcopenia } \\
(\text { EWGSOP) } \\
(\mathbf{n}=44)\end{array}$ & $\begin{array}{c}\text { Frailty } \\
(\text { Fried) } \\
(\mathbf{n}=94)\end{array}$ & $\begin{array}{c}\text { Cachexia } \\
(\text { Evans) } \\
(\mathbf{n}=\mathbf{2 0})\end{array}$ & $\begin{array}{c}\text { Total } \\
\text { sample } \\
(\mathbf{n}=95)\end{array}$ \\
\hline Barthel index & $36.5(27.7)$ & $38.8(28.2)$ & $48(30.6)$ & $42.4(29.0)$ & $48.3(30.6)$ \\
\hline Institutionalization & $6(31.6 \%)$ & $7(15.9 \%)$ & $15(16.0 \%)$ & $4(20 \%)$ & $15(15.8 \%)$ \\
\hline Readmissions & $3(15.8 \%)$ & $8(18.2 \%)$ & $19(20.2 \%)$ & $3(15 \%)$ & $19(20 \%)$ \\
\hline Mortality & $3(15.8 \%)$ & $5(11.4 \%)$ & $12(12.8 \%)$ & $2(10 \%)$ & $12(12.6 \%)$ \\
\hline
\end{tabular}

(*) Data are expressed as numbers and percentages for categorical variables, and as mean and standard deviation (SD) for continuous variables. List of abbreviations. ESPEN: European Society of Clinical Nutrition and Metabolism; EWGSOP: European Working Group on Sarcopenia in Older People; BMI: Body mass index; SD: Standard deviation. 
Table 3. Factors affecting Barthel index at 3-month follow-up, according to clinical characteristics, components of malnutrition as defined by the ESPEN consensus and nutrition-related conditions.

\begin{tabular}{|c|c|c|c|c|}
\hline \multicolumn{5}{|c|}{ Barthel indexat 3-month follow-up } \\
\hline & \multicolumn{2}{|c|}{ Univariate analysis } & \multicolumn{2}{|c|}{ Multivariate analysis } \\
\hline & $\begin{array}{l}\text { Median difference } \\
(95 \% \mathrm{CI})\end{array}$ & $\mathbf{p}$ & $\begin{array}{l}\text { Median difference } \\
(95 \% \mathrm{CI})\end{array}$ & $\mathbf{p}$ \\
\hline Clinical characteristics & & & & \\
\hline $\begin{array}{l}\text { Age } \\
\text { Sex } \\
\text { Comorbidity (Charlson }>2 \text { ) } \\
\text { Unintentional weight loss }\end{array}$ & $\begin{array}{c}-2(-3.50 \text { to }-0.50) \\
15(-8.47 \text { to } 38.47) \\
0(-6.21 \text { to } 6.21) \\
-12(-34.91 \text { to }-10.91)\end{array}$ & $\begin{array}{c}0.009 \\
0.208 \\
1.00 \\
0.301\end{array}$ & $\begin{array}{c}-2.19(-7.28 \text { to } 2.89) \\
\mathbf{1 8 . 0 5}(-\mathbf{- 0 . 4 1} \text { to } 36.51) \\
-2.19(-7.28 \text { to } 2.89) \\
-5.29(-29.28 \text { to } 18.69)\end{array}$ & $\begin{array}{l}0.393 \\
\mathbf{0 . 0 5 5} \\
0.393 \\
0.662\end{array}$ \\
\hline $\begin{array}{l}\text { Malnutrition and nutrition } \\
\text { conditions }\end{array}$ & & & & \\
\hline Malnutrition & $-20(-46.65$ to 6.65$)$ & 0.139 & $-14.10(-46.06$ to 17.87$)$ & 0.383 \\
\hline Sarcopenia & $-25(-43.22$ to -6.78$)$ & 0.008 & $-25.49(-46.66$ to -4.32$)$ & 0.019 \\
\hline Overweight-obesity & $15(-8.86$ to 38.86$)$ & 0.215 & $0.24(-20.58$ to 21.07$)$ & 0.981 \\
\hline Nutrient deficiency & $0(-22.18$ to 22.18$)$ & 1.000 & $12.93(-5.31$ to 31.17$)$ & 0.162 \\
\hline Cachexia & $-15(-41.65$ to 11.65$)$ & 0.266 & $11.83(-18.60$ to 42.25$)$ & 0.441 \\
\hline
\end{tabular}


Table 4. Factors affecting institutionalization at 3-month follow-up, according to clinical characteristics, components of malnutrition as defined by the ESPEN consensus and nutrition-related conditions.

\begin{tabular}{|l|c|c|c|c|}
\hline \multicolumn{4}{|c|}{ Institutionalizationat 3-month follow-up } \\
\hline & \multicolumn{2}{|c|}{ Univariate analysis } & \multicolumn{2}{c|}{ Multivariate analysis } \\
\hline & Odds ratio (95\% CI) & $\mathbf{p}$ & Odds ratio (95\%CI) & $\mathbf{p}$ \\
\hline Clinical characteristics & & & & \\
& & & & \\
Age & $1.08(0.99$ to 1.19$)$ & 0.083 & $\mathbf{1 . 1 4}(\mathbf{1 . 0 1}$ to 1.28) & $\mathbf{0 . 0 3 3}$ \\
Sex & $\mathbf{0 . 3 2}(\mathbf{0 . 1 0}$ to 1.0$)$ & $\mathbf{0 . 0 0 5}$ & $\mathbf{0 . 1 8}(\mathbf{0 . 0 4}$ to 0.72) & $\mathbf{0 . 0 1 6}$ \\
Comorbidity (Charlson>2) & $0.88(0.63$ to 1.22$)$ & 0.443 & $0.85(0.58$ to 1.25$)$ & 0.420 \\
Unintentional weight loss & $\mathbf{3 . 9 5}(\mathbf{1 . 2 6}$ to 12.41) & $\mathbf{0 . 0 1 8}$ & $\mathbf{5 . 4 6}(\mathbf{0 . 9 4}$ to 31.62) & $\mathbf{0 . 0 5 8}$ \\
& & & & \\
\hline Malnutrition and nutrition-related & & & & \\
conditions & & & & \\
Malnutrition & & & & \\
Sarcopenia & & & & \\
Overweight-obesity & $\mathbf{3 . 4 4 ( 1 . 0 4}$ to 11.31) & $\mathbf{0 . 0 4 2}$ & $3.69(0.34$ to 40.27$)$ & 0.285 \\
Nutrient deficiency & $1.02(0.34$ to 3.07$)$ & 0.976 & $1.51(0.28$ to 8.17$)$ & 0.629 \\
Cachexia & $1.33(0.42$ to 4.27$)$ & 0.628 & $2.53(0.49$ to 13.15$)$ & 0.268 \\
& $0.9(0.29$ to 2.78$)$ & 0.855 & $0.63(0.16$ to 2.50$)$ & 0.511 \\
& $1.45(0.41$ to 5.17$)$ & 0.563 & $0.58(0.05$ to 6.30$)$ & 0.657 \\
\hline
\end{tabular}


Table 5. Factors affecting readmissions at 3-month follow-up, according to clinical characteristics, components of malnutrition as defined by ESPEN consensusand nutrition-related conditions.

\begin{tabular}{|c|c|c|c|c|}
\hline \multicolumn{5}{|c|}{ Readmissions at 3-month follow-up } \\
\hline & \multicolumn{2}{|c|}{ Univariate analysis } & \multicolumn{2}{|c|}{ Multivariate analysis } \\
\hline & $\begin{array}{l}\text { Odds ratio } \\
(95 \% \mathrm{CI})\end{array}$ & $\mathbf{p}$ & Odds ratio $(95 \% \mathrm{CI})$ & $\mathbf{p}$ \\
\hline \multicolumn{5}{|l|}{ Clinical characteristics } \\
\hline Age & $0.93(0.91$ to 1.56$)$ & 0.074 & $0.93(0.85$ to 1.01$)$ & 0.095 \\
\hline Sex & $1(0.35$ to 2.83$)$ & 1 & $1.09(0.35$ to 3.37$)$ & 0.879 \\
\hline Comorbidity (Charlson $>2$ ) & $1.19(0.91$ to 1.56$)$ & 0.211 & $1.18(0.88$ to 1.59$)$ & 0.269 \\
\hline Unintentional weight loss & $0.94(0.32$ to 2.77$)$ & 0.913 & $0.82(0.19$ to 3.47$)$ & 0.784 \\
\hline \multicolumn{5}{|c|}{$\begin{array}{l}\text { Malnutrition and nutrition-related } \\
\text { conditions }\end{array}$} \\
\hline Malnutrition & $0.70(0.18$ to 2.71$)$ & 0.609 & $0.91(0.13$ to 6.44$)$ & 0.929 \\
\hline Sarcopenia & $0.81(0.29$ to 2.23$)$ & 0.681 & $1.03(0.27$ to 3.88$)$ & 0.964 \\
\hline Overweight-obesity & $0.85(0.30$ to 2.36$)$ & 0.752 & $0.59(0.17$ to 2.07$)$ & 0.408 \\
\hline Nutrient deficiency & $1.41(0.48$ to 4.12$)$ & 0.527 & $1.33(0.42$ to 4.17$)$ & 0.623 \\
\hline Cachexia & 0.66 ( 0.17 to 2.50$)$ & 0.532 & $0.52(0.08$ to 3.58$)$ & 0.506 \\
\hline
\end{tabular}


Table 6. Factors affecting postdischarge mortality, according to clinical characteristics, components of malnutrition as defined by the ESPEN consensus and nutrition-related conditions.

\begin{tabular}{|c|c|c|c|c|}
\hline \multicolumn{5}{|c|}{ Postdischarge mortality } \\
\hline & \multicolumn{2}{|c|}{ Univariate analysis } & \multicolumn{2}{|c|}{ Multivariate analysis } \\
\hline & Odds ratio $(95 \% \mathrm{CI})$ & p & Odds ratio $(95 \% \mathrm{CI})$ & $\mathbf{p}$ \\
\hline \multicolumn{5}{|l|}{ Clinical characteristics } \\
\hline Age & $1.05(1.01$ to 1.09$)$ & 0.005 & $1.08(1.03$ to 1.13$)$ & 0.001 \\
\hline Sex & $1.01(0.61$ to 1.69$)$ & 0.964 & $1.10(0.65$ to 1.87$)$ & 0.718 \\
\hline Comorbidity (Charlson $>2$ ) & $1.11(0.98$ to 1.27$)$ & 0.105 & $1.15(1.0$ to 1.33$)$ & 0.053 \\
\hline Unintentional weight loss & $1.10(0.616$ to 1.85$)$ & 0.711 & $1.20(0.56$ to 2.55$)$ & 0.641 \\
\hline \multicolumn{5}{|c|}{$\begin{array}{l}\text { Malnutrition and nutrition-related } \\
\text { conditions }\end{array}$} \\
\hline Malnutrition & $1.21(0.67$ to 2.18$)$ & 0.534 & $1.28(0.52$ to 3.11$)$ & 0.589 \\
\hline Sarcopenia & $1.03(0.63$ to 1.69$)$ & 0.896 & $0.85(0.44$ to 1.63$)$ & 0.625 \\
\hline Overweight-obesity & $1.04(0.62$ to 1.72$)$ & 0.889 & $1.09(0.57$ to 2.10$)$ & 0.788 \\
\hline Nutrient deficiency & $1.07(0.64$ to 1.76$)$ & 0.800 & $1.13(0.66$ to 1.94$)$ & 0.654 \\
\hline Cachexia & $0.98(0.53$ to 1.80$)$ & 0.940 & $0.88(0.39$ to 2.01$)$ & 0.772 \\
\hline
\end{tabular}


Figure 1. Readmissions curves by malnutrition as defined by the ESPEN consensus

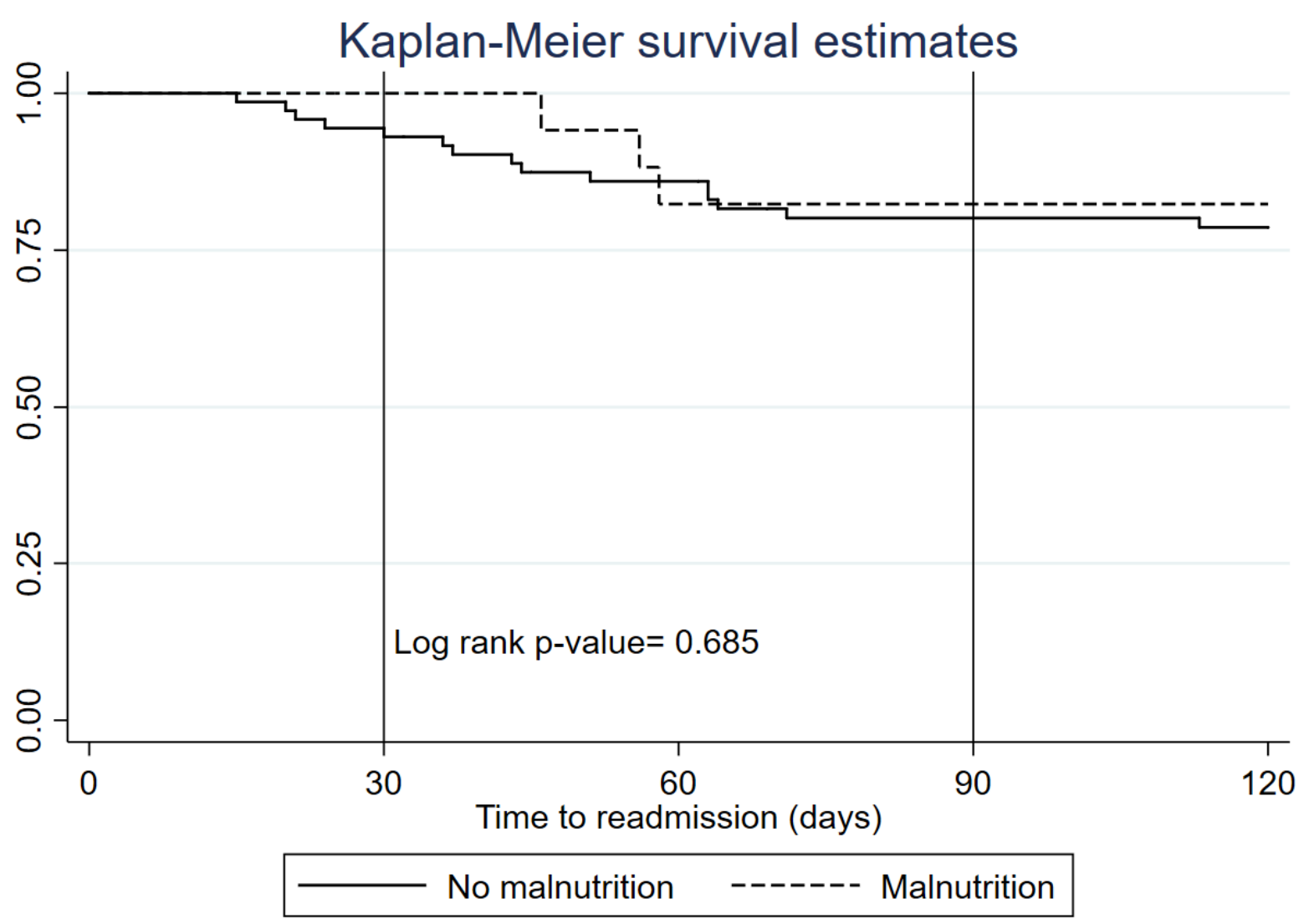


Figure 2. Survival curves by malnutrition as defined by the ESPEN consensus

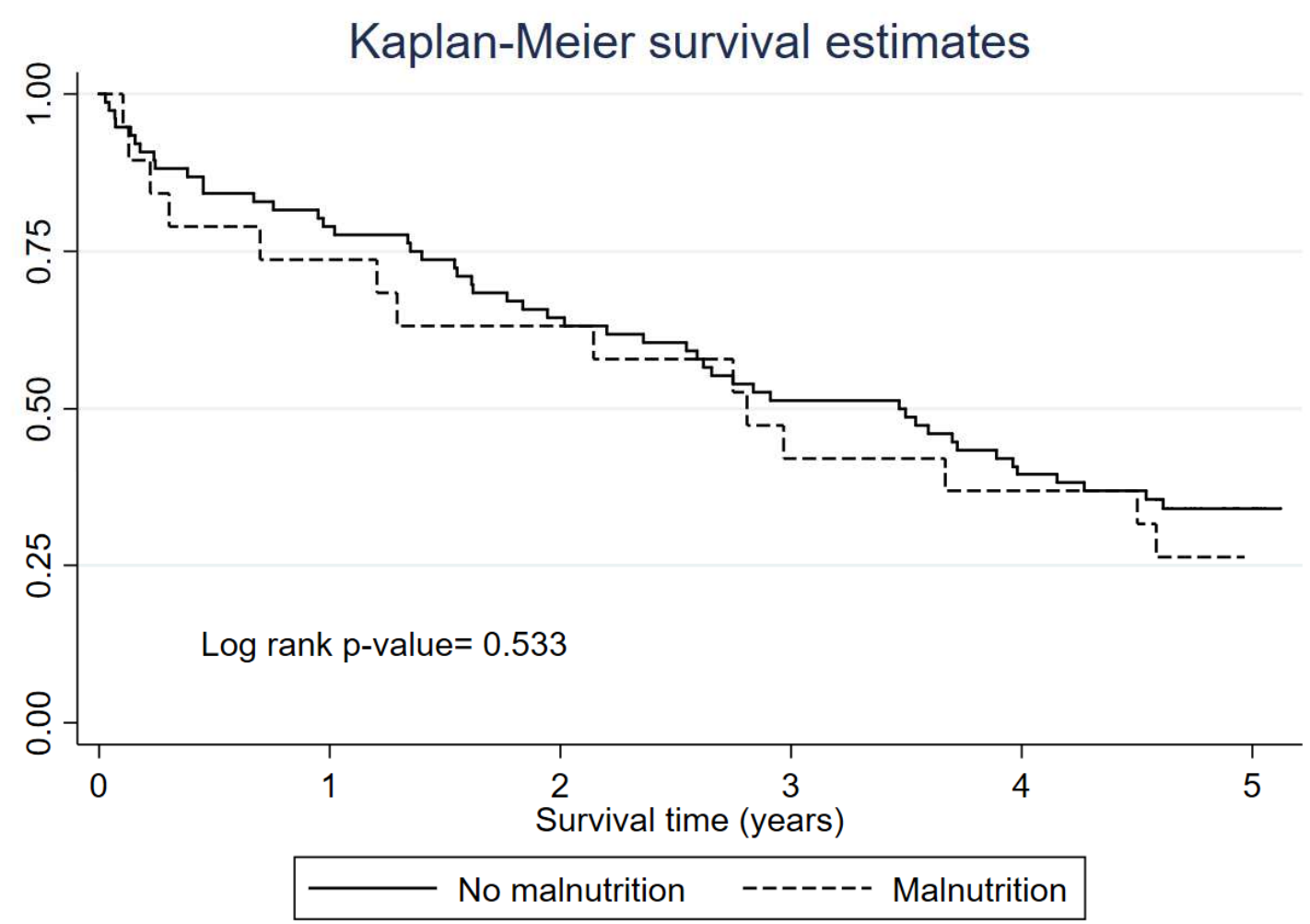


1

2

3

4

5

6

7

8

9

10

STROBE Statement —Checklist of items that should be included in reports of cohort studies: Prognostic value of the ESPEN consensus and guidelines for malnutrition: Prediction of post-discharge clinical outcomes in older inpatients

\begin{tabular}{lcl} 
& $\begin{array}{c}\text { Item } \\
\text { No }\end{array}$ & \multicolumn{1}{c}{ Recommendation } \\
\hline Title and abstract & 1 & $\begin{array}{l}\text { (a) Indicate the study's design with a commonly used term in the title or the abstract } \\
\text { (Title page, Abstract) }\end{array}$ \\
& & $\begin{array}{l}\text { Abstract } \\
\text { (b) Provide in the abstract an informative and balanced summary of what was done } \\
\text { and what was found }\end{array}$ \\
\hline Introduction & Abstract \\
\hline Background/rationale & 2 & Explain the scientific background and rationale for the investigation being reported \\
\hline Objectives & & Page1 \\
\hline
\end{tabular}

Page 2

\begin{tabular}{lll}
\hline Methods & \\
\hline Study design & $\begin{array}{l}\text { Present key elements of study design early in the paper } \\
\text { Page 3 }\end{array}$ \\
\hline Setting & $\begin{array}{l}\text { Describe the setting, locations, and relevant dates, including periods of recruitment, } \\
\text { exposure, follow-up, and data collection }\end{array}$ \\
& $\begin{array}{l}\text { Page 3 } \\
\text { Participants }\end{array}$ \\
& $\begin{array}{l}\text { participants. Describe methods of follow-up } \\
\text { Page 3 }\end{array}$ \\
\hline
\end{tabular}

(b) For matched studies, give matching criteria and number of exposed and unexposed

Not applicable: this was not a matched study

Variables

7 Clearly define all outcomes, exposures, predictors, potential confounders, and effect modifiers. Give diagnostic criteria, if applicable

Pages 3-4: procedure and data collection

Pages 4-6: variables and diagnostic criteria

Page 4-6: outcome variables

Exposures, predictors, potential confounders, and effect modifiers are not applicable to our study. 


\begin{tabular}{lll}
$\begin{array}{l}\text { Data sources/ } \\
\text { measurement }\end{array}$ & $8^{*}$ & $\begin{array}{l}\text { For each variable of interest, give sources of data and details of methods of } \\
\text { assessment (measurement). Describe comparability of assessment methods if there is } \\
\text { more than one group }\end{array}$ \\
& $\begin{array}{l}\text { Pages 5-6: calculation and cut-off points of outcomes measures; data source for all } \\
\text { variables }\end{array}$ \\
\hline Bias & $\begin{array}{l}\text { Describe any efforts to address potential sources of bias } \\
\text { Page 12, efforts to minimize errors and bias }\end{array}$ \\
\hline Study size & $\begin{array}{l}\text { Explain how the study size was arrived at } \\
\text { Prospective cohort study of all inpatients admitted in postacute care during study } \\
\text { period }\end{array}$ \\
\hline Quantitative variables & $\begin{array}{l}\text { Explain how quantitative variables were handled in the analyses. If applicable, } \\
\text { describe which groupings were chosen and why }\end{array}$ \\
\hline Statistical methods & $\begin{array}{l}\text { Page 4-6: variables, cut-off points of main outcome variables } \\
\text { Table 1, } 2\end{array}$ \\
\hline $\begin{array}{l}\text { (a) Describe all statistical methods, including those used to control for confounding } \\
\text { Page 8-9, Statistical Methods paragraph }\end{array}$
\end{tabular}

(b) Describe any methods used to examine subgroups and interactions

Pages 6-7

(c) Explain how missing data were addressed

Pages 13 (patients unable to stand)

(d) If applicable, explain how loss to follow-up was addressed

Not applicable

(e) Describe any sensitivity analyses

Not applicable

\begin{tabular}{ll}
\hline Results & $13^{*}$ \\
\hline Participants & $\begin{array}{l}\text { (a) Report numbers of individuals at each stage of study-eg numbers potentially } \\
\text { eligible, examined for eligibility, confirmed eligible, included in the study, } \\
\text { completing follow-up, and analysed }\end{array}$ \\
& Page 8, Table 1 and 2 \\
\hline
\end{tabular}

(b) Give reasons for non-participation at each stage

Not applicable

(c) Consider use of a flow diagram

Not applicable

Descriptive data $\quad 14^{*} \quad$ (a) Give characteristics of study participants (eg demographic, clinical, social) and information on exposures and potential confounders

Page 8 and Tables 1 and 2

http://mc.manuscirptcentral.com/ncp 
(b) Indicate number of participants with missing data for each variable of interest

Page 8 and Tables 1 and 2

(c) Summarise follow-up time (eg, average and total amount)

Page 3

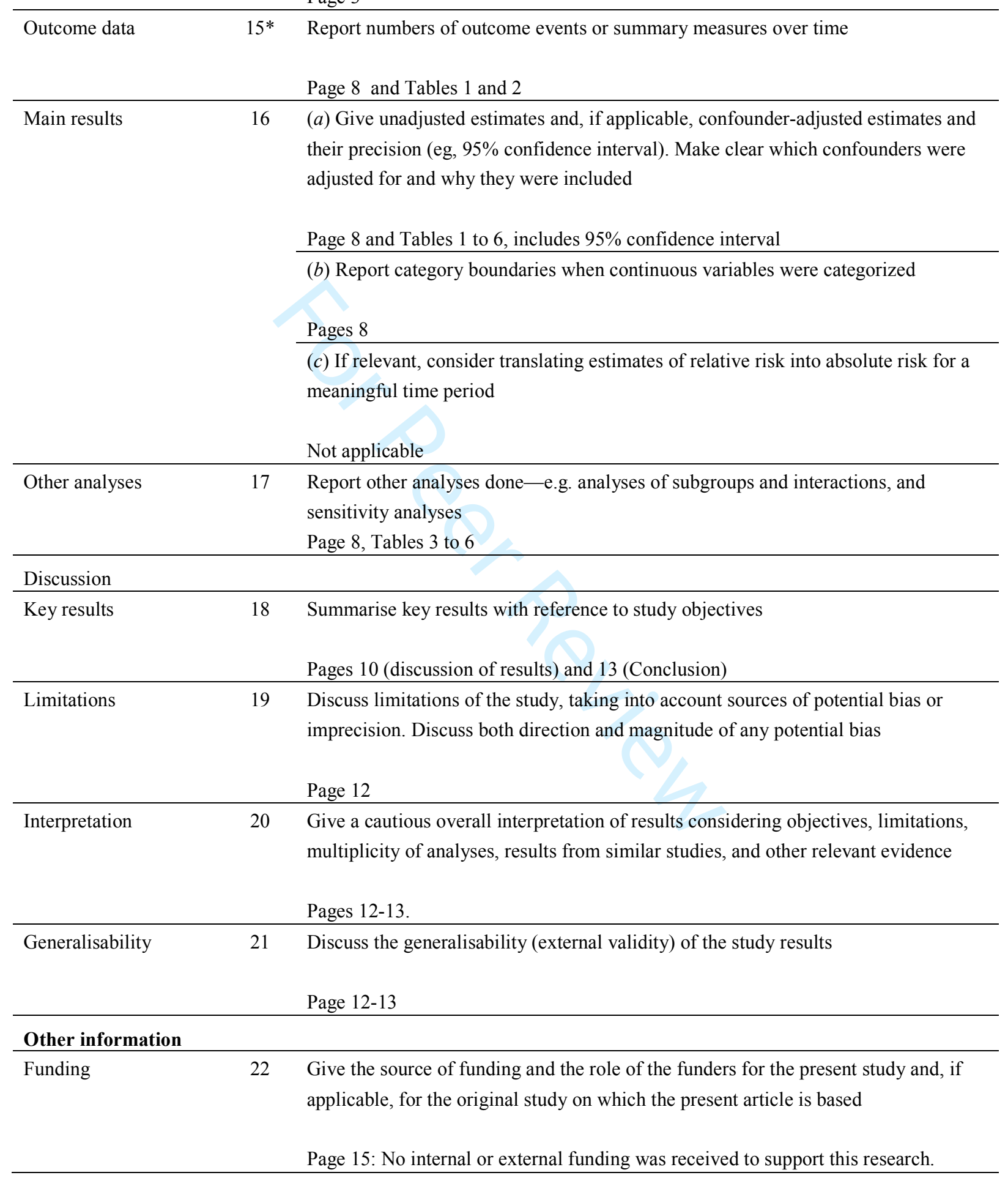

*Give information separately for exposed and unexposed groups. 
Note: An Explanation and Elaboration article discusses each checklist item and gives methodological background and published examples of transparent reporting. The STROBE checklist is best used in conjunction with this article (freely available on the Web sites of PLoS Medicine at http://www.plosmedicine.org/, Annals of Internal Medicine at http://www.annals.org/, and Epidemiology at http://www.epidem.com/). Information on the STROBE Initiative is available at http://www.strobe-statement.org. 